\title{
Unification and Expansion of Wade-Mingos Rules with Elementary Number Theory
}

\author{
ENOS MASHEIJA KIREMIRE \\ Department of Chemistry and Biochemistry, University of Namibia, \\ Private Bag 13301, Windhoek, Namibia. \\ ${ }^{*}$ Corresponding author E-mail: kiremire15@yahoo.com \\ http://dx.doi.org/10.13005/ojc/310146
}

(Received: December 01, 2014; Accepted: January 12, 2015)

\begin{abstract}
The study of clusters by using the empirical formula $k=1 / 2(E-V)$ revealed the existence of cluster series. This gave rise to the design of a cluster table that has been highly refined to its current form in this paper. On closer scrutiny of the cluster table has further revealed an infinite number of cluster series based upon $4 \mathrm{n}$ for main group elements which obey octet rule and $14 \mathrm{n}$ for transition metal elements which obey the 18 electron rule. The cluster series decrease successively in valence electron count by 2 or increase successively by 2 . The Wade-Mingos rules based upon $4 n, 5 n$ and $6 n$ rules (polyhedral skeletal electron pair theory) all belong to the $4 n-$ based cluster series of the cluster table are a subset of many series. This may simply be regarded as a unification and expansion of Wade-Mingos rules. The table is very simple to use to study clusters by students at secondary, undergraduate and postgraduate levels.
\end{abstract}

Key words: Wade-Mingos Rules, Elementary number theory.

\section{INTRODUCTION}

The Wade-Mingos rules have been exceedingly useful in the study of boranes, carboranes, main group element and transition metal carbonyl clusters for more than four decades ${ }^{1-}$ ${ }^{3}$. These rules are referred to as $4 n, 5 n$, and $6 n$ rules with which a geometry and cluster classification of a given cluster is determined. These rules refereed to as polyhedral skeletal electron pair theory (PSEPT) are now well known ${ }^{1-3}$.
The Birth of the Empirical Formula $k=1 / 2(E-V)$

While teaching a topic on Lewis structures of molecules at an undergraduate level, a desire to look for a simple formula that could assist students in drawing Lewis structures was mooted. In the search for the simple formula, $\mathrm{N}_{2}$ diatomic molecule was considered first ${ }^{4}$. When the two $\mathrm{N}$ atoms are brought together to form the $\mathrm{N}_{2}$ molecule with a triple bond, the two sets of five valence electrons are arranged in such a way that a triple bond is formed and each of the two $\mathrm{N}$ atoms then obeys the octet rule. By sheer intuition, it occurred that 
doubling the octet electrons and subtracting the double valence electrons of $\mathrm{N}$ atom and then dividing by two, a value of 3 was obtained. This was the birth of the empirical formula $k=1 / 2(E-V)$ where $E=2 \times 8=16, V=2 \times 5=10$ and $k=1 / 2(16-10)=3$. This meant that the formula gives us the triple bond that links up the $\mathrm{N}_{2}$ atoms and by just inserting a lone pair on each $\mathrm{N}$ atom, a Lewis structure is constructed. What is fascinating is that the empirical formula simple as it is, is applicable to all diatomic and polyatomic systems whose atoms obey the octet rule. For instance, when the formula is applied to the diatomic species $\mathrm{C}_{2}(\mathrm{E}=16, \mathrm{~V}=8, \mathrm{k}=4), \mathrm{CN}^{+}(\mathrm{E}=$ $16, \mathrm{~V}=4+5-1=8, \mathrm{k}=4), \mathrm{BN}(\mathrm{E}=16, \mathrm{~V}=3+5=8, \mathrm{k}=$ $4)$, and $\mathrm{CB}^{-}(\mathrm{E}=16, \mathrm{~V}=4+3+1=8, \mathrm{k}=4$ ) the value of $k=4$ was obtained in agreement with the recent theoretical studies ${ }^{5}$.This observation that these diatomic species are held together by a quadruple bond underpins the power of the empirical formula.

\section{Designing the Cluster Code}

After determining the $k$ values of many clusters, there was a need to design a label to distinguish them. In the case of $\mathrm{N}_{2}$, we have two atoms (M-2), $k$ value of 3 and a total of 10 valence electrons. But also in $\mathrm{CO}$ molecule, there are two atoms (M-2), $\mathrm{k}=3$ and 10 valence electrons. Therefore it made sense to label the diatomic molecules such as $\mathrm{N}_{2}$ and $\mathrm{CO}$ as $\mathrm{M}-2-3-10$. In the case of $\mathrm{C}_{2}$ and its analogues, the label becomes $M$ 2-4-8. Thus, a method for coding clusters was designed as $\mathrm{M}-\mathrm{x}-\mathrm{k}-\mathrm{V}$ where $\mathrm{M}$ refers to the element in the cluster, $\mathrm{k}=$ number of bonds or linkages that hold the cluster system together and $\mathrm{V}$ is the total valence electrons of the cluster. When the $\mathrm{C}_{2}$ with code $\mathrm{M}-2-4-8$ is converted into $\mathrm{C}_{2} \mathrm{H}_{2}$ by adding two hydrogen atoms $\mathrm{k}$ becomes 3 , that is, $\mathrm{k}=3$ the triple bond of acetylene $\mathrm{H}-\mathrm{Cl} \mathrm{C}-\mathrm{H}$. The two $\mathrm{H}$ atoms may be regarded as 'ligands' to the $\mathrm{C}_{2}$ diatomic system. The code then changes to $\mathrm{M}-2-3-10$ as in $\mathrm{N}_{2}$. The method of calculating $\mathrm{k}$ value for lager clusters is the same. For instance, $P_{4}[E=4 \times 8=32$, $\mathrm{V}=4 \times 5=20, \mathrm{k}=1 / 2(32-20)=6$, code $M-4-6-20$, tetrahedral $]^{6}, \mathrm{~B}_{5} \mathrm{H}_{9}[\mathrm{E}=5 \times 8=40, \mathrm{~V}=5 \times 3+9=24, \mathrm{k}=$ $1 / 2(40-24)=8$, code $=M-5-8-24$, square pyramid $]^{7}$, $\mathrm{B}_{5} \mathrm{H}_{5}{ }^{2}[\mathrm{E}=5 \times 8=40, \mathrm{~V}=5 \times 3+5+2=22, \mathrm{k}=9$, code $\mathrm{M}-$ 5-9-22, trigonal bipyramid $]^{6}$, andB ${ }_{6} \mathrm{H}_{6}{ }^{-}[\mathrm{E}=6 \times 8=48$, $\mathrm{V}=6 \times 3+6+2=26, \mathrm{k}=11$, code $\mathrm{M}-6-11-26$, octahedral $]^{6}$.In the case of transition metal carbonyl clusters, the same empirical formula will apply but
$\mathrm{E}=$ will refer to the total 18 electron system of the 'skeletal' atoms and $\mathrm{V}=$ the total valence electrons of metal atoms and all the ligands and any embedded atoms involved. Take the examples, $\mathrm{Mn}_{2}(\mathrm{CO})_{10}[\mathrm{E}=2 \times 18=36, \mathrm{~V}=2 \times 7+10 \times 2=34, \mathrm{k}=1 / 2$ $(36-34)=1, \mathrm{M}-2-1-34]^{8}, \mathrm{Os}_{3}(\mathrm{CO})_{12}[\mathrm{E}=54, \mathrm{~V}=48, \mathrm{k}$ $=3, \mathrm{M}-3-3-48$,triangle $]^{8}, \operatorname{Ir}_{4}(\mathrm{CO})_{12}[\mathrm{E}=72, \mathrm{~V}=60, \mathrm{k}=$ 6, M-4-6-60, tetrahedral $]^{8}, \mathrm{Os}_{5}(\mathrm{CO})_{16}[\mathrm{E}=90, \mathrm{~V}=72$, $\mathrm{k}=9, \mathrm{M}-5-9-72$, trigonal bipyramid $]^{8}$ and $\mathrm{Os}_{6}(\mathrm{CO}){ }_{18}{ }^{2}[\mathrm{E}=108, \mathrm{~V}=86, \mathrm{k}=11, \mathrm{M}-6-11-86$, octahedral $]^{8}$.

\section{Origin of the Cluster Table and the Unification and Expansion of Wade-Mingos Rules}

After analyzing the $k$ values of many clusters, it was clear that the clusters follow a numerical sequence of numbers based on an alternating series of even and odd numbers. Hence, a cluster table was designed. Table 1 gives clusters ranging from two skeletal atoms (M-2) to ten (M-10). Ideally, the table can be extended in all directions.As you move down a column from the top, you traverse clusters of the same number of atoms $M-x$ but different $k$ values.For instance, we can move from $\mathrm{M}-2-4-8\left(\mathrm{C}^{1} \mathrm{C}\right)$ represented by say $\mathrm{C}_{2}$ to $\mathrm{M}-2-3-10$ (C) represented by $\mathrm{N}_{2}$. Diagonal movement is simply a capping process in which $\mathrm{k}$ changes by 3 units("k = 3). For example movement from M-5-8$24\left[\mathrm{Fe}_{5}(\mathrm{C})(\mathrm{CO})_{14}{ }^{2^{-}} \text {, square pyramid }\right]^{9}$ to M-6-11-86$\mathrm{C}\left[\mathrm{Os}_{6}(\mathrm{CO})_{18}{ }^{2^{-}} \text {, octahedral }\right]^{9}$ is a capping process. When this capping process or movement along the diagonal is carefully analyzed,it is discovered that it forms the basis upon which Rudolph's table is constructed $^{10}$. An interesting constant ratio $\mathrm{x}: \mathrm{k}: \mathrm{V}$ $=1: 2: 4$ for main group elements and 1:2:14 for transition metal carbonyl clusters was identified for $\mathrm{C}^{1} \mathrm{C}$ (monocapped) series. For instance, M-2-4-8, ratio is $1: 2: 4$ and $2 \times 4=8$, and also $M-10-20-40$ ratio is $1: 2: 4$ and $10 \times 4=40$ and so on. Clearly, this is the $4 n$ series. In the case of the closo $(C)$ series, M-2-3$10, n=2$ and $4 n+2=10$ and $M-6-11-26, n=6$ and $4 n+2=26$. Clearly, this is $4 n+2$ series. It was readily discernible that all the main group element series were based upon $4 \mathrm{n}$ while those of the transition metal carbonyls based upon $14 \mathrm{n}$ (where $\mathrm{n}$ refers to the number of skeletal elements in the cluster).All the selected cluster series and their relationship to $4 n$ and $14 n$ are shown in the Table 1.It is fascinating that the widely used polyhedral skeletal electron paircluster seriessuch as $4 n-2$ (bicapped closo), $4 n$ 


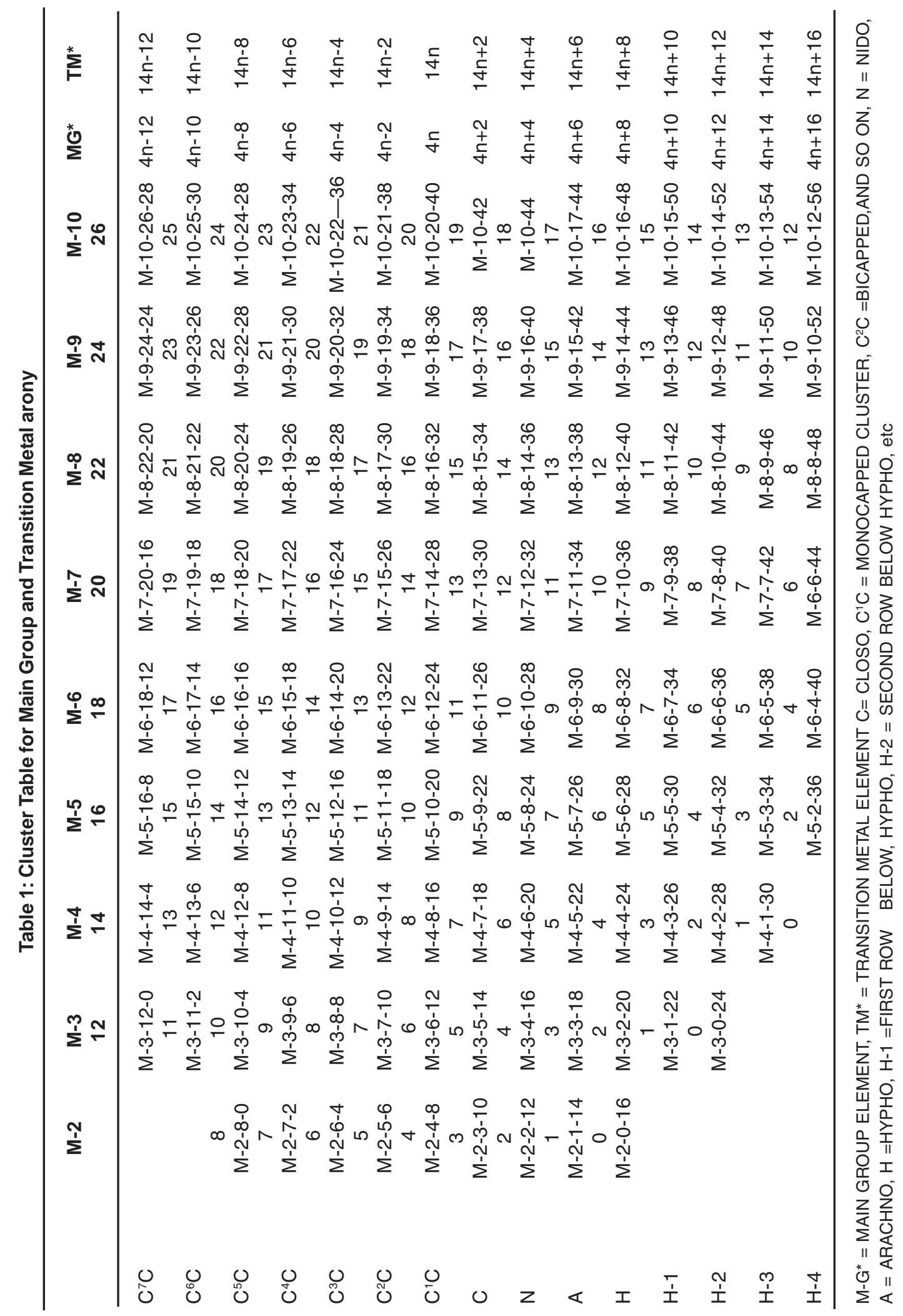


(monocapped closo), $4 n+2$ (closo), $4 n+4$ (nido), $4 n+6$ (arachno) and $4 n+8$ (hypho) are inclusive as a subset of many series in Table 1. This tantamount to the unification and expansion of Wade-Mingos rules. Thus, on close examination, this table revealed the hidden natural law of the cluster series as follows: from the monocapped series, $C^{1} \mathrm{C}(4 n)$ upwards, we have $(4 n-2)$ for bicapped series $\left(C^{2} C\right)$, (4n-4), (4n-6), (4n-8), (4n-10), (4n-12) and so on and downwards, $(4 n+2)$ for closo series $(C),(4 n+4)$ for nido series $(N),(4 n+6),(4 n+8),(4 n+10),(4 n+12)$ and so on for main group element clusters. On the other hand for the corresponding transition metal carbonyl clusters we have for the monocapped cluster series $C^{1} C(14 n)$ andmoving upwards, we get (14n-2), (14n-4), (14n-6), (14n-8), (14n-10), $(14 n-12)$ and so on andmoving downwards in the table, the series $(14 n+2),(14 n+4),(14 n+6),(14 n+8)$, $(14 n+10),(14 n+12)$ and so on are obtained.

\section{Categorizing a Cluster with the Cluster Table}

Using the empirical formula $k=1 / 2(E-V)$ and the cluster Table 1, a given cluster can readily be categorized. For a example, $\mathrm{Rh}_{6}(\mathrm{CO})_{16}[\mathrm{E}=6 \mathrm{X} 18$ $=108, \mathrm{~V}=6 \mathrm{X} 9+16 \mathrm{X} 2=86, \mathrm{k}=1 / 2(\mathrm{E}-\mathrm{V})=1 / 2(108-86)$ $=11, M-6-11-86)$. By moving down the M-6 column reaching M-6-11-86,then moving across the row it is found that the cluster belongs to the closo (C) series $M-6-11-86-C(14 n+2)$ with an octahedral geometry ${ }^{8}$. Similarly, $\mathrm{Rh}_{7}(\mathrm{CO})_{16}{ }^{3}(\mathrm{M}-7-14-98)$ belongs to the monocapped series, $C^{1} C(14 n)^{11}$. The capping is on an octahedral geometry which is diagonally below it in the closo (C) series. The complex, $\mathrm{Os}_{8}(\mathrm{CO})_{22}{ }^{2-}$ has the cluster parameters $[\mathrm{E}$ $=8 \times 18=144, \mathrm{~V}=8 \times 8+22 \times 2+2=110, \mathrm{k}=1 / 2(\mathrm{E}-\mathrm{V})=$ $1 / 2(144-110)=17, M-8-17-110]$. Moving down the M-8 column until M-8-17-110, then moving across the row we encounter $\mathrm{C}^{2} \mathrm{C}$. This means the complex is bicapped octahedral ${ }^{11}$ since it lies on the diagonal

Table 2: Correlation between Wade-Mingos and Cluster Table on Series

\begin{tabular}{lccccc}
\hline Cluster & W-M* & CT $^{*}$ & Electrons & W-M Type & CT Type \\
\hline $\mathrm{Rh}_{6}(\mathrm{CO})_{16}$ & $4 \mathrm{n}+2$ & $4 \mathrm{n}+2$ & $86(26$ main group table $)$ & $\mathrm{C}$ & $\mathrm{C}$ \\
$\mathrm{Os}_{6}(\mathrm{CO})_{18}$ & $4 \mathrm{n}$ & $4 \mathrm{n}$ & $84(24$ main group $)$ & $\mathrm{C}^{-1} \mathrm{C}$ & $\mathrm{C}^{-1} \mathrm{C}$ \\
$\mathrm{Pb}_{10}{ }^{-2}$ & $4 \mathrm{n}+2$ & $4 \mathrm{n}+2$ & 42 & $\mathrm{C}$ & $\mathrm{C}$ \\
$\mathrm{Se}_{4}{ }^{2+}$ & $4 \mathrm{n}+6$ & $4 \mathrm{n}+6$ & 22 & $\mathrm{~A}$ & $\mathrm{~A}$ \\
$\mathrm{~B}_{5} \mathrm{H}_{5}{ }^{4-}$ & $4 \mathrm{n}+4$ & $4 \mathrm{n}+4$ & 24 & $\mathrm{~N}$ & $\mathrm{~N}$ \\
$\mathrm{C}_{2} \mathrm{~B}_{7} \mathrm{H}_{13}$ & $4 \mathrm{n}+6$ & $4 \mathrm{n}+6$ & 42 & $\mathrm{~A}$ & $\mathrm{~A}$ \\
$\mathrm{P}_{4}$ & $5 \mathrm{n}$ & $4 \mathrm{n}+4$ & 20 & - & $\mathrm{N}$ \\
$\mathrm{P}_{4} \mathrm{~S}_{3}$ & $5 \mathrm{n}+3$ & $4 \mathrm{n}+10$ & 38 & - & $\mathrm{H}-1$ \\
$\mathrm{P}_{4} \mathrm{O}_{6}$ & $5 \mathrm{n}+6$ & $4 \mathrm{n}+16$ & 56 & - & $\mathrm{H}-4$ \\
$\mathrm{~S}_{8}$ & $6 \mathrm{n}$ & $4 \mathrm{n}+16$ & 48 & - & $\mathrm{H}-4$ \\
$\mathrm{C}_{6} \mathrm{H}_{14}$ & $6 \mathrm{n}+2$ & $4 \mathrm{n}+14$ & 38 & - & $\mathrm{H}-3$ \\
\hline
\end{tabular}

$\mathrm{W}-\mathrm{M}^{*}=$ Wade-MINGOS, $\mathrm{CT}=$ Cluster table

where the closo $(\mathrm{C})$ geometry below it is octahedral. The complex also belongs to the $\mathrm{C}^{2} \mathrm{C}$ cluster series $(14 \mathrm{n}-2 ; 8 \times 14-2=110)$. Another cluster, $\mathrm{Os}_{9}(\mathrm{CO})_{24}{ }^{2-}$ has the following cluster parameters $[E=9 \times 18=162$, $\mathrm{V}=9 \times 8+24 \times 2+2=122, \mathrm{k}=20, \mathrm{M}-9-20-122]$. By tracing $\mathrm{M}-9$ column, the complex is found to belong to $C^{3} \mathrm{C}(14 \mathrm{n}-4 ; 14 \times 9-4=122)$ series. This is a tricapped octahedral ${ }^{12}$. Finally, the complex, $\mathrm{Os}_{10}(\mathrm{CO})_{26}{ }^{2-}$ has the parameters $[\mathrm{E}=180, \mathrm{~V}=134, \mathrm{k}$ $=23, \mathrm{M}-10-23-134]$. The cluster belongs to $\mathrm{C}^{4} \mathrm{C}(14 \mathrm{n}-$ $6 ; 14 \times 10-6=134)$ series. This is a tetracapped octahedral geometry ${ }^{11}$ since it is diagonally above octahedral in the closo(C) series. The change in $\mathrm{k}$ value by 3 is characteristic of the capping process. For instance, $\mathrm{k}=11$ for octahedral $(\mathrm{C}), \mathrm{k}=11+3=14$ for monocapped geometry $\left(\mathrm{C}^{1} \mathrm{C}\right), \mathrm{k}=11+3+3=17$ for bicapped geometry $\left(C^{2} C\right), k=11+3+3+3=20$ for tricapped geometry and $k=11+3+3+3+3=23$ for tetracpped geometry $\left(\mathrm{C}^{4} \mathrm{C}\right)$.

\section{Using the Cluster Table to Interpret some Literature work}

Let us consider the following examples. The complex, $\mathrm{Felr}_{4}(\mathrm{CO})_{15}{ }^{2}{ }^{2}(1)$ and $\mathrm{Fe}_{2} \mathrm{Ir}_{3}(\mathrm{CO})_{14}{ }^{-}(2)$ 
were found to have a trigonal bipyramid shapes but the former was more elongated in axial positions than the later ${ }^{13}$. The complex 1 has the cluster code $M-5-7-76-A$ and 2 has the code M-5-9-72-C. The reason for this could be due to the fact the two complexes belong to different series. The complex $\mathrm{Os}_{10}(\mathrm{CO})_{24}{ }^{2-}$ was described as having a tetracapped octahedral geometry ${ }^{13}$. The cluster parameters for the complex are $[E=180, \mathrm{~V}=10 \times 8+24 \times 2+2=130$, $\mathrm{k}=1 / 2(E-V)=1 / 2(180-130)=25, M-10-25-130]$. When we scan its diagonal below it, we encounter the following cluster code series: $\mathrm{M}-10-25-130\left(\mathrm{C}^{6} \mathrm{C}\right)>\mathrm{M}-$ 9-22-118( $\left.\mathrm{C}^{5} \mathrm{C}\right)>\mathrm{M}-8-19-106\left(\mathrm{C}^{4} \mathrm{C}\right)>\mathrm{M}-7-16-$ $94\left(C^{3} \mathrm{C}\right)>M-6-13-82\left(C^{2} \mathrm{C}\right)$. This means that the complex is not a tetracapped geometry based on an octahedral shape whose code is M-6-11-86(C) but rather on the geometry with a code M-6-13$82\left(\mathrm{C}^{2} \mathrm{C}\right)$. The cluster that is tetracapped based on the octahedral geometry will have a value deduced as follows $\mathrm{k}=11+3+3+3+3=23$. This corresponds to a cluster code of $\mathrm{M}-10-23-134\left(\mathrm{C}^{4} \mathrm{C}\right)$. As mentioned above, one such a cluster is $\mathrm{Os}_{10}(\mathrm{CO})_{26}{ }^{{ }^{-}}$ complex and not $\mathrm{Os}_{10}(\mathrm{CO})_{24}{ }^{{ }^{-}}$complex. Thus, the cluster table could be of great assistance in understanding and re-interpreting some literature data.

\section{The Cluster Table on CO stripping Experiments}

The cluster table can be very helpful in understanding and appreciating the 'CO stripping' experiments. In this regard, Mclndoe and his research teams have tremendously done a $\operatorname{lot}^{14-18}$. Their EDESI-MS studies have studied many carbonyl complexes ${ }^{14}$ including $\mathrm{HOs}_{5}(\mathrm{CO})_{15}{ }^{-}$, $\mathrm{PtRu}_{5}(\mathrm{C})(\mathrm{CO})_{15}{ }^{2^{-}}, \mathrm{Os}_{10}(\mathrm{C})(\mathrm{CO})_{24}{ }^{2^{-}}, \mathrm{Os}_{17}(\mathrm{CO})_{36}{ }^{3^{-}}$, $\mathrm{Co}_{6}(\mathrm{C})(\mathrm{CO})_{15}{ }^{2-}, \mathrm{Pt}_{3} \mathrm{Ru}_{10}(\mathrm{C})_{2}(\mathrm{CO})_{32}{ }^{2^{-}}$, and $\mathrm{Pd}_{6} \mathrm{Ru}_{6}$ $(\mathrm{CO})_{24}{ }^{2}$. What is of great interest with EDESI-MS studies is that the decomposition intermediates of the initial cluster can be monitored by observing the peaks of the intermediate cluster species. For instance, $\mathrm{HOs}_{5}(\mathrm{CO})_{15}{ }^{-}$was completely stripped naked by removal of all $\mathrm{CO}$ ligands to $\mathrm{HOs}_{5}{ }^{-}$ complex ${ }^{14}$. The initial cluster has the code M-5-972-C. It is likely to possess a trigonal bipyramid shape.During decomposition, for every loss of one CO ligand, the valence electrons decrease by two and the $k$ value increases by one. Hence, the changes from $\mathrm{HOs}_{5}(\mathrm{CO})_{15}{ }^{-}$toHOs $_{5}{ }^{-}$may be expressed by the cluster code as follows: M-5-972-C> M-5-10-70>M-5-11-68>M-5-12-66>M-5-13-
$64>\mathrm{M}-5-14-62>\mathrm{M}-5-15-60>\mathrm{M}-5-16-58>\mathrm{M}-5-17-$ $56>M-5-18-54>M-5-19-52>M-5-20-50>M-5-21-$ $48>M-5-22-46>M-5-23-44>M-5-24-42$. It will be useful to investigate whether the completely naked cluster $\mathrm{HOs}_{5}{ }^{-}$could be isolated. This particular experiment could be considered as an example of a movement along the $\mathrm{M}-5$ high way in the cluster table. The EDESI-MS studies vindicate the significance of the cluster table.

\section{Correlation between the Cluster Table and Wade- Mingos Rules on Cluster Series}

The cluster Table 1 analyzes a wide range of clusters for both main group elements and transition metals. It is therefore of great interest to find out how the table relates to Wade-Mingos rules of $4 n, 5 n$ and $6 n$. In this regard, it became necessary to use the cluster table approach to study some of the examples on which Wade-Mingos rules were applied. The examples tabulated below were taken from the website ${ }^{19}$. The selected examples are given in Table 2. As can be seen from Table 2, the cluster table approach arrives at identical series for monocapped series $(4 n)$, closo series $(4 n+2)$, nido series $(4 n+4)$ and arachno series $(4 n+6)$ as the Wade-Mingos rules. However, all the $5 n$ series of Wade-Mingo rules in Table 2 have been found to fit in the Cluster Table $4 \mathrm{n}$ series. For instance, $\mathrm{P}_{4}$ classified as a member of $5 n$ by Wade-Mingos rules is found to be a member of $4 n+4$ (Nido) series. The $\mathrm{P}_{4} \mathrm{~S}_{3}$ classified as $5 n+3$ under Wade-Mingos rules is a member of $4 n+10$ under the Cluster Table approach. For $\mathrm{P}_{4} \mathrm{O}_{6}(5 n+6)$ under Wade-Mingos rules becomes $4 n+16$ under cluster table. $S_{8}$ becomes $6 n$ under Wade-Mingos rules but is a member of $4 n+16$ under cluster table approach, and $\mathrm{C}_{6} \mathrm{H}_{14}$ is $6 \mathrm{n}+2$ by Wade-Mingos approach but also a member of $4 n+14$ using the cluster table. Using the cluster table, the $4 n$-based series cover the clusters of the main group elements while the corresponding $14 n$-based series cover the clusters of the transition metal clusters.

\section{CONCLUSION}

The cluster table is a strong confirmation of Wade-Mingos rules. Furthermore, the table indicates that the clusters from small ones(M-2) to large clusters as (M-40) and bigger can be analyzed by the table in its present form which can be 
expanded as needed. All the clusters with skeletal atoms that obey either octet or 18 electron rule which can be analyzed by Wade-Mingos rules can also be readily categorized using the cluster table.The clusters of the main group elements whose systems obey the octet rule are based upon $4 n$ series while the transition metal carbonyl clusters (skeletal elements must obey the 18 electron rule) are based on $14 \mathrm{n}$ series. The difference in electron count between corresponding series is $10 \mathrm{n}$. By using the cluster $\mathrm{k}$ value and the cluster table, a cluster can be categorized. The cluster table for clusters can regarded in the same manner as the periodic table for elements. This approach of categorizing clusters is so easy that it could be taught to students in secondary school, undergraduate and postgraduate levels.

\section{REFERENCES}

1. Wade, K, J. Chem. Soc., Dalton, 1971, 972793.

2. Mingos, D. M. P., Nature Physical Science, 1972, 236, 99-102.

3. Welch, A. J., Chem. Comm., 2013, 49, 36153616.

4. Kiremire, E.M. R., Materials Science Research India, 2006, 3(2a), 205-214.

5. Shaik, S., Danovich, D., Wu, W., Su, P., Rzepa, H. S., Hiberty, P., S., Nature Chemistry, 2012, 1-5.

6. McGlinchey, M. J., Hopf, H., Beilstein, J. Org.Chem., 2011, 7, 222-233.

7. Greenwood, N. N.; Earnshaw, A. Chemistry of the Elements, $2^{\text {nd }}$ Edition, Butterworth and Heinemann, Oxford, 1998.

8. Housecroft, C. E., Sharpe, A. G., Inorganic Chemistry, $2^{\text {nd }}$ Edition, Pearson, Prentice Hall, Harlow, England, 2005.

9. Zanello, P. Unusual Structures and Physical Properties in Organometallic Chemistry, Edited Gielen, M.; Wrackmeyer,B. John Wiley and Sons, New York, 2002

10. Rudolph, R. W., Acc. Chem. Res., 1976, 9, 446-452.
11. Teo, B. K., Longoni, G., Chung, F. R. K., Inorg. Chem., 1984, 23, 1257-1266.

12. Hughes, A. K., Wade, K., Coord. Chem. Rev., 2000, 197, 191-229.

13. Mingos, D. M. P., Pure and Appl. Chem., 1991,63(6), 807-812.

14. Butcher, C. P. G,, Dyson, P.J., Johnson, B. F. G., Khimyak, T., Mclndoe, J. S., Chem. Eur. J., 2003, 9(4), 944-950.

15. Crawford, E., Dyson, P. J., Forest, O., Kwok, S., Mclndoe, J. S., J. Cluster Science, 2006, 17(1), 47-63.

16. Henderson, M. A., Kwok, S., McIndoe, J. S., J. Am. Soc. Mass Spectrom., 2009,20, 658666.

17. Butcher, C.P. G., Johnson, B. F. G., Mclndoe, J. S., J. Chem. Phy., 2002, 116(15), 65606566.

18. Critchley, G., Johnson, B. F. G., Mclndoe, J. S., O’Reilly, R. K., Langridge-Smith, P. R. R., Organometallics, 1999,18,4090-4097.

19. En.wikipedia.org/wiki/polyhedral_ skeletal_electron_pair:theory. Downloaded 26-01-2015. 